\title{
Strategi Media Relations Praxis dalam Membangun Corporate Image Bank DBS Indonesia
}

\author{
Joses Karsten, Sinta Paramita \\ joseskarsten04@gmail.com,sintap@fikom.untar.ac.id
}

Fakultas Ilmu Komunikasi Universitas Tarumanagara

\begin{abstract}
Indonesia has now entered an era of rapid technological and internet development, which also requires the financial services industry to be able to follow it. This is indicated by the intense competition between banks in Indonesia that have started to develop their services in the form of digital banking. To overcome this problem, the thing done by Praxis as the PR Agency of Bank DBS Indonesia is to build an image as a bank that is not complicated in banking activities through a mission that is also a key message "Live more, Bank less". In this case, the effort made by Praxis is to implement a media relations strategy to gain mass media publicity. The main theoretical of this research uses media relations theory, specifically regarding to the concept of media relations strategy by Yosal Iriantara (2011). This research uses a qualitative approach with a descriptive-study case method. The results of this research reveal that the media relations strategy implemented by Praxis are manage good relations with the media, develop strategies that produce general principles in doing media relations, and also develop a wider job network.
\end{abstract}

Keywords: digital banking, image, media relations, public relations.

\begin{abstract}
Abstrak
Indonesia kini telah memasuki era perkembangan teknologi dan internet yang begitu pesat, dimana mengharuskan juga industri jasa dibidang keuangan untuk dapat mengikutinya. Hal ini ditandai dari ketatnya persaingan antar bank di Indonesia yang sudah mulai mengembangkan layanan mereka ke dalam bentuk digital banking. Untuk mengatasi permasalahan tersebut, upaya yang dilakukan oleh Praxis sebagai PR Agency dari Bank DBS Indonesia adalah dengan membangun citra sebagai bank yang tidak ribet dalam urusan perbankan melalui misi yang sekaligus merupakan pesan kunci "Live more, Bank less" kepada publik. Dalam hal ini, upaya yang dilakukan oleh Praxis adalah dengan melaksanakan strategi media relations guna meraih publisitas media massa. Landasan teori utama penelitian ini menggunakan teori media relations, khususnya mengenai konsep strategi media relations oleh Yosal Iriantara (2011). Penelitian ini menggunakan pendekatan kualitatif dengan metode studi kasus-deskriptif. Hasil temuan penelitian ini mengemukakan bahwa strategi media relations yang diterapkan Praxis adalah dengan mengelola relasi yang baik dengan media, mengembangkan strategi yang melahirkan prinsip umum dalam melaksanakan media relations, serta yang terakhir adalah mengembangkan jaringan pekerjaan yang lebih luas.
\end{abstract}

Kata Kunci: citra, media relations, perbankan digital, public relations.

\section{Pendahuluan}

Seiring dengan berkembangnya zaman dan kemajuan teknologi, telah menyebabkan perubahan baik di bidang sosial, ekonomi, maupun budaya yang berlangsung dengan sangat cepat. Dengan keadaan seperti ini, industri jasa dibidang keuangan, khususnya perbankan pun juga diharuskan untuk dapat mengikuti 
perkembangan tersebut. Hal ini juga terjadi di Indonesia, dimana perusahaan perbankan dituntut untuk mulai mengembangkan layanan mereka ke dalam bentuk aplikasi digital. Dari hasil riset yang dilakukan oleh McKinsey \& Company bertema Asia's Digital Banking Rrace: Giving Customers What They Want pada April 2018, terjadi pergeseran yang cukup signifikan dalam penggunaan aplikasi digital untuk melakukan transaksi sehari-hari. Pada kantor cabang berbagai bank di Asia, kini hanya menangani sekitar $12 \%$ hingga $21 \%$ dari layanan transaksi nasabah setiap bulannya. Berdasarkan riset tersebut juga, sebanyak 55\% hingga 80\% nasabah di Asia akan mempertimbangkan pilihan mereka untuk beralih ke digital banking. (https://finansial.bisnis.com/read/20180703/90/812401/persaingan-semakin-ketat-diperbankan-digital. Diakses 30 September 2019 pukul 21:00).

Dengan adanya fenomena ini, membuat persaingan antar bank pun semakin ketat. Berbagai bank di Indonesia pun berlomba-lomba untuk dapat memberikan layanan perbankan digital yang terbaik bagi nasabah mereka. Hal ini juga dirasakan oleh Bank DBS dengan produk perbankan digitalnya yang resmi masuk ke Indonesia pada tahun 2017. Dalam meraih hati dan kepercayaan publik, selain dengan meningkatkan fitur-fitur perbankan digitalnya, lewat misi "Live more, Bank less", Bank DBS Indonesia juga membangun citra sebagai bank yang tidak ribet dalam urusan perbankannya (https://marketeers.com/makna-slogan-live-more-bank-lessuntuk-bank-dbs/. Diakses 30 September 2019 pukul 22:00).

Hal inilah yang menjadi tugas dan fungsi utama Public Relations perusahaan. Selain menjadi komunikator baik ke dalam maupun ke luar perusahaan, Public Relations juga memiliki fungsi khusus untuk membangun citra perusahaan. Dalam kasus ini, Public Relations Bank DBS Indonesia tidak bekerja sendiri, namun juga bekerja bersama salah satu Public Relations Agency yang berbasis di Jakarta, yaitu PT Prima Praxis Komunika (Praxis). Salah satu cara yang dilakukan oleh Praxis dalam meraih publisitas adalah dengan melaksanakan strategi media relations. Pada umumnya, pengertian dari strategi adalah kebijakan yang kemudian dijabarkan ke dalam sejumlah taktik untuk mencapai tujuan perusahaan (Iriantara, 2011). Sedangkan menurut Savitri, Setyanto, \& Winduwati (2016), strategi komunikasi merupakan paduan perencanaan komunikasi dengan manajemen komunikasi untuk mencapai tujuan yang telah ditetapkan. Pada dasarnya, Media relations sendiri merupakan salah satu fungsi atau salah satu unit kerja divisi Public Relations yang memiliki pengertian bagaimana Public Relations membangun suatu hubungan kerjasama yang berdasarkan simbiosis mutualisme atau bersifat saling menguntungkan antara Public Relations dengan wartawan media (Farleni \& Widayatmoko, 2014).

Oleh sebab itu, Peneliti tertarik untuk melakukan penelitian mengenai strategi media relations yang dilakukan Praxis dalam membangun citra Bank DBS Indonesia. Sedangkan dipilihnya Bank DBS Indonesia sebagai topik pembahasan penelitian ini adalah karena permasalahan yang dimiliki oleh Bank DBS Indonesia sedang menjadi bahasan terkini, khususnya di Indonesia, dimana banyak perusahaan perbankan yang juga sudah mulai mengembankan pelayanan mereka lewat bantuan teknologi digital dan internet, yang disebut juga dengan layanan digital banking.

\section{Metode Penelitian}

Penelitian ini menggunakan pendekatan kualitatif dengan metode studi kasusdeskriptif. Menurut Lodico, Spaulding, \& Voegtle, penelitian kualitatif merupakan suatu metodologi yang dipinjam dari disiplin ilmu sosiologi dan antropologi yang 
diadaptasi ke dalam dunia Pendidikan (Emzir, 2016). Sedangkan metode penelitian deskriptif merupakan penelitian yang berusaha mendeskripsikan suatu gejala, peristiwa, kejadian, yang terjadi pada saat sekarang (Sudjana \& Ibrahim, 2009). Untuk itu, Peneliti menggunakan metode penelitian deskriptif karena Peneliti ingin mendeskripsikan dan menggambarkan bagaimana upaya Praxis dalam membangun citra dari Bank DBS Indonesia melalui strategi media relations yang diterapkan.

Subjek dalam penelitian ini adalah praktisi $P R$ Praxis yang berurusan langsung dengan klien Bank DBS Indonesia (tim DBS). Moleong (2018) mendeskripsikan subjek penelitian sebagai informan, yaitu orang yang dapat memberikan informasi tentang situasi dan kondisi latar penelitian. Dalam kasus ini key informan yang dipilih Ayu Nurul Huda, Associate Praxis dan Nadya Ayuningtyas, Account Coordinator Praxis. Sedangkan informan yang dipilih adalah orang yang turut serta mengetahui dan menilai kinerja tim DBS, yaitu Adwi Yudiansyah, Director Praxis, Selfy Momongan, Wartawan Kumparan.com, Vinsensia Ariesta Dianawanti, Wartawan Liputan6.com, dan Maria Trisnawati, Wartawan Stabilitas. Sedangkan objek penelitian ini adalah kajian keilmuan mengenai Public Relations yang berfokus pada strategi media relations yang diterapkan oleh Praxis dalam membangun citra Bank DBS Indonesia.

Teknik pengumpulan data yang dilakukan dibagi menjadi dua, yaitu data primer dan data sekunder. Menurut Sugiyono (2014), data primer adalah data yang langsung diperoleh dari pemberi data (sumber) secara langsung. Sedangkan data sekunder adalah data yang tidak langsung diperoleh dari pemberi data atau sumber, melainkan dari sumber lainnya. Dalam penelitian ini, data primer diperoleh melalui teknik observasi langsung dan juga wawancara mendalam. Dan data sekunder dalam penelitian ini diperoleh dari sumber-sumber dokumen yang terkait dan juga studi kepustakaan berupa buku atau penelitian terdahulu

Metode analisis data yang digunakan dalam penelitian ini adalah dengan pereduksian data, penyajian data, serta Penarikan kesimpulan dan verifikasi (Sugiyono, 2014). Teknik keabsahan data yang digunakan dalam penelitian ini adalah triangulasi, yaitu teknik pemeriksaan data yang memanfaatkan hal yang lain di luar data untuk keperluan pengecekan terhadap data yang dimiliki. Terdapat empat macam teknik triangulasi data, yaitu triangulasi dengan sumber, triangulasi dengan metode, dan triangulasi dengan teori (Moleong, 2018).

\section{Hasil Temuan dan Diskusi}

Dalam membangun citra perusahaan kliennya, yaitu Bank DBS Indonesia, tentunya Praxis menerapkan strategi media relations, dimana di dalamnya Praxis juga menjalankan fungsi utama dari Public Relations, yaitu dalam hal penyebaran informasi kepada publik lewat bantuan media massa, serta membangun citra perusahaan (Ruslan, 2002). Berikut penjelasan satu persatu strategi media relations yang dijalankan oleh Praxis dalam membangun citra Bank DBS Indonesia.

\section{Mengelola relasi}

Dalam strategi mengelola relasi, yang dilakukan oleh Praxis adalah dengan membangun hubungan yang bersifat formal dan juga informal terhadap berbagai media, khususnya wartawan. Hubungan formal yang dibangun oleh praktisi $P R$ Praxis dengan wartawan adalah hubungan yang berlandaskan kebutuhan pekerjaan diantara dua profesi yang berbeda, seperti pada saat media event dan sebagainya. Sedangkan hubungan informal yang dibangun oleh praktisi $P R$ Praxis merupakan hubungan yang 
lebih bersifat personal. Bentuk kegiatannya beragam, mulai dari melakukan pertemuan makan siang bersama, nonton film bersama, dan berbagai aktivitas lainnya yang dilakukan layaknya hubungan antar pertemanan.

Hal ini sesuai dengan pernyataan dari Yosal Iriantara (2011), membangun hubungan dengan media dibagi menjadi dua, yaitu dilakukan secara profesional antara dua pihak yang berbeda bidang tugasnya (formal), serta hubungan yang sifatnya personal berdasarkan hubungan antar manusia (informal). Tentunya bentuk dari strategi mengelola relasi dengan media yang dilakukan Praxis, baik secara formal maupun informal merupakan strategi yang sangat berguna untuk dapat terus menjalin hubungan kerjasama jangka panjang yang baik dengan media massa.

\section{Mengembangkan strategi}

Setelah hubungan terjalin dengan baik, langkah selanjutnya adalah dengan mengembangkan strategi. Strategi utama yang dilakukan oleh Praxis adalah dengan mengkomunikasikan key message yang dimiliki oleh Bank DBS Indonesia berupa selogan, yaitu "Live more, Bank less" kepada publik. Dengan adanya key message tersebut, tentunya akan membantu menyampaikan tujuan dan apa yang ingin dicapai oleh Bank DBS Indonesia. Selain itu, strategi yang dikembangkan Praxis dalam menjalankan praktik media relations juga merujuk pada prinsip umum dalam melaksanakan media relations oleh Jefkins (Darmastuti, 2012), yaitu:

1. By serving the media

Dalam upaya mempererat hubungan yang baik dengan media, salah satu strategi yang dilakukan praktisi $P R$ Praxis adalah dengan menyediakan apa yang dibutuhkan oleh wartawan. Berikut penuturan yang diberikan oleh Ayu Nurul Huda:

“... Karena pada akhirnya selain kita memberikan informasi, kalau mereka butuh informasi lebih lanjut, mereka masih ada informasi yang kurang, mereka bisa kasih tau kita pertanyaan-pertanyaannya apa, ... So, pada akhirnya kita serving the media better. Ga cuman sekedar kita butuh berita, tapi kita juga mengakomodir kalau mereka ada butuh apa-apa, gitu." (Hasil wawancara dengan Ayu Nurul Huda, Associate Praxis, Kamis 10 Oktober 2019).

Bentuk pelayanan utama yang diberikan oleh praktisi $P R$ Praxis kepada rekan media adalah dengan menyediakan materi pemberitaan dalam bentuk press release baik hard copy maupun soft copy. Selain itu, Praxis juga mengutamakan ketepatan waktu dalam penyebaran rilis. Ketepatan waktu merupakan hal yang sangat penting bagi media, karena media dituntut untuk dapat menyajikan berita yang aktual. Hal ini juga sejalan dengan salah satu dari lima prinsip dasar yang menjadi pedoman dalam berhubungan dengan media, yaitu memperhatikan tenggat waktu media (Iriantara, 2011). Dengan memberikan rilis diawal acara tentunya hal ini dapat mempermudah dan mempercepat wartawan dalam menyajikan dan mempublikasikan berita.

2. By establishing a reputation for reliability

Dalam membangun reputasi dan kepercayaan, strategi yang dilakukan Praxis adalah dengan selalu menyediakan sumber pemberitaan yang terpercaya. Salah satunya adalah dengan selalu memastikan narasumber yang menyampaikan materi adalah narasumber kredibel dibidangnya, sehingga mencukupi nilai berita. Karena bagaimanapun juga, reputasi Praxis dalam menyediakan materi pemberitaan juga berpengaruh pada reputasinya sebagai 
PR Agency. Hal ini juga dibenarkan oleh Maria Trisnawati, Wartawan Stabilitas terkait penyediaan narasumber yang kredibel dan sesuai dengan bidangnya.

“... Biasanya sih kalau Praxis yah biasanyakan event yah, narasumber yang diundang itu yang pasti kredibel. Soalnya kalau misalnya dia ngomong tentang menggaet anak muda untuk berinvestasi atau menggunakan Digibank, itu ya bener-bener dia harus ngundang anak muda atau pengusaha muda yang berhasil dan bisa kita kutip." (Hasil wawancara dengan Maria Trisnawati, Wartawan Stabilitas, Jumat 29 November 2019).

Narasumber kredibel yang diundang pun bisa dari berbagai bidang, sesuai dengan topik pembahasan yang sedang disampaikan. Dengan menyediakan narasumber yang kredibel dan sesuai pada bidangnya, maka wartawan pun dapat memberikan rasa percaya mereka terhadap bahan informasi atau materi pemberitaan yang disediakan oleh Praxis.

3. By supplying good copy

Dalam bekerjasama dengan media, penyediaan bahan informasi merupakan hal yang sangat penting. Hal ini dilakukan dengan memberikan salinan press release yang memiliki kandungan isi materi atau konten yang memiliki nilai berita. Upaya yang dilakukan Praxis adalah dengan selalu mengembangkan materi $P R$ atau konten rilis yang mereka sediakan dengan menyesuaikan pada apa yang sedang ramai diperbincangkan di kalangan media dan juga masyarakat.

“... Kita pakai angle yang relevan dengan media tersebut. Jadi sebelum merangkai group interview/exclusive interview itu, Praxis approach, mendekati jurnalis-jurnalis dan menanyakan, Mas/Mbak, kira-kita yang lagi in tuh trend-nya apa sih, ... Karena kalau misalkan apa yang mereka cari dan apa yang kita tawarkan ga match ya ga bakal nyambung dong, gitu." (Hasil wawancara dengan Nadya Ayuningtyas, Account Coordinator Praxis, Rabu 9 Oktober 2019).

Hal ini sesuai dengan pernyataan Yosal Iriantara (2011) mengenai salah satu prinsip dalam menjalankan strategi media relations, yaitu terus mengembangkan materi $P R$. Dengan menyesuaikan isi materi press release dengan topik bahasan yang sedang ramai diperbincangkan di kalangan publik, tentunya dapat lebih menarik perhatian media untuk memberitakannya juga.

4. By cooperation in providing material

Dalam upaya membangun citra Bank DBS Indonesia, selain menyediakan materi pemberitaan berbentuk rilis, Praxis juga mengadakan berbagai aktivitas media relations guna membangun kerjasama yang lebih baik lagi dengan wartawan, seperti press conference, media briefing, dan juga wawancara eksklusif (Hasil wawancara dengan Nadya Ayuningtyas, Account Coordinator Praxis, Rabu 9 Oktober 2019).

Dengan diselenggarakannya berbagai media event ini, tentunya materi pemberitaan pun akan lebih bervariasi dan dapat lebih menarik perhatian wartawan dalam menyajikan berita. Upaya dalam meraih publisitas dapat terlaksana dengan baik. Selain itu, dengan diselenggarakannya berbagai media event ini, bermanfaat juga bagi Bank DBS Indonesia dalam menyampaikan pesan kepada media secara lebih efektif dan efisien. 


\section{By providing verification facilities}

Praktisi $P R$ Praxis tentunya juga memfasilitasi wartawan media untuk melakukan verifikasi data ataupun bentuk informasi lainnya secara langsung kepada mereka. Hal ini juga merupakan salah satu bentuk komunikasi yang dilakukan secara formal, dimana para praktisi $P R$ Praxis selalu siap apabila dihubungi oleh wartawan yang hendak mengkonfirmasi terkait informasi mengenai Bank DBS Indonesia. Sedangkan untuk beberapa kasus lainnya, materi informasi secara langsung yang disampaikan pada saat acara seperti press conference terkadang belum jelas didengar dan diterima baik oleh wartawan. Hal seperti ini yang biasanya mendorong mereka untuk memperoleh informasi lebih dan secara langsung. Dalam hal ini, Praxis juga turut membantu wartawan dengan menyediakan waktu secara khusus untuk mengadakan doorstop interview yang langsung dari narasumber terkait.

Gambar 1. Door Doorstop Interview dengan Sri Mulyani

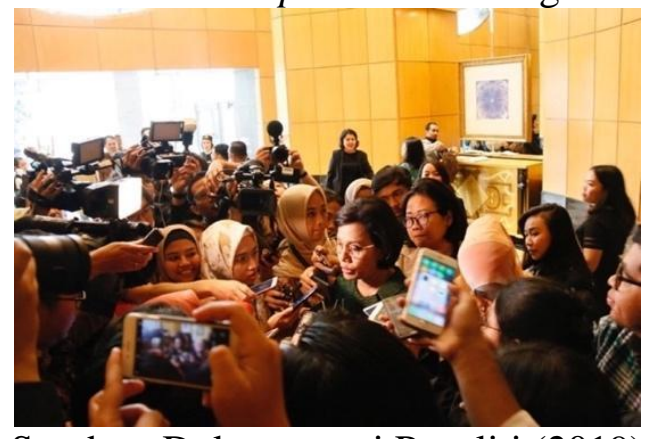

Sumber: Dokumentasi Peneliti (2019)

6. By building personal relationship with the media

Praxis selalu berusaha membangun hubungan personal yang baik dengan media. Hal ini juga tertunya bertujuan agar kerjasama yang dilakukan dapat berjalan dengan baik dan bertahan lama untuk jangka panjang. Tidak hanya kepada wartawan saja, membangun hubungan yang baik juga dilakukan Praxis dengan media secara keseluruhan, baik dengan bagian Redaksi, Editor, ataupun juga dengan Account Executive dari media.

Tentunya dalam strategi membangun hubungan personal ini memiliki tujuan untuk dapat menjalin kerjasama yang bersifat jangka panjang. Salah satu manfaat yang dapat diperoleh adalah apabila Bank DBS Indonesia sedang mengalami isu yang tidak begitu jelas, sehingga media pun dapat meredam pemberitaan dan tidak dengan asal mempublikasikannya (Hasil wawancara dengan Nadya Ayuningtyas, Account Coordinator Praxis, Rabu 9 Oktober 2019).

\section{Mengembangkan jaringan}

Strategi yang terakhir adalah mengembangkan jaringan. Salah satu bentuk mengembangkan jaringan yang dilakukan oleh Praxis adalah dengan melakukan media visit ke berbagai kantor media. Dengan adanya kerjasama ini, maka dalam hal pemberitaan dan publikasi pun akan dapat berjalan lebih baik lagi. Selain mengembangkan jaringan dengan media, seringkali Praxis juga mengembangkan jaringan dengan berbagai komunitas/instansi profesi yang berbeda. Contohnya adalah dengan komunitas olahraga INDOSWEATCAMP pada kampanye DBS Runnin' Berlin dan juga dengan pemerintah kota Bekasi pada program CSR People of Purpose. 
Lewat mengembangkan jaringan pekerjaan dengan berbagai institusi/komunitas di bidang profesi yang berbeda ini, tentunya materi pemberitaan pun akan menjadi lebih menarik, sehingga akan lebih mudah juga dalam meraih publisitas. Hal ini sesuai dengan pernyataan dari Yoshal Iriantara, yaitu dalam mengembangkan jaringan relasi tidak hanya dilakukan dengan organisasi yang memiliki bidang profesi yang sama saja, melainkan juga dengan berbagai bidang profesi lainnya, seperti perusahaan media, atau bahkan dengan organisasi yang jauh di luar bidang profesi. Dengan memperluas jaringan dengan berbagai komunitas/instansi profesi yang berbeda, ada kemungkinan dan berpeluang salah satu anggota dari mereka dapat dijadikan narasumber pada acara yang diselenggarakan. Hal ini juga tentunya berpeluang lebih untuk media melakukan pemberitaan dan publisitas oleh karena materi dan nilai berita yang baik (Iriantara, 2011).

Gambar 2. Bekerjasama dengan Pemerintah Kota Bekasi dalam kegiatan CSR

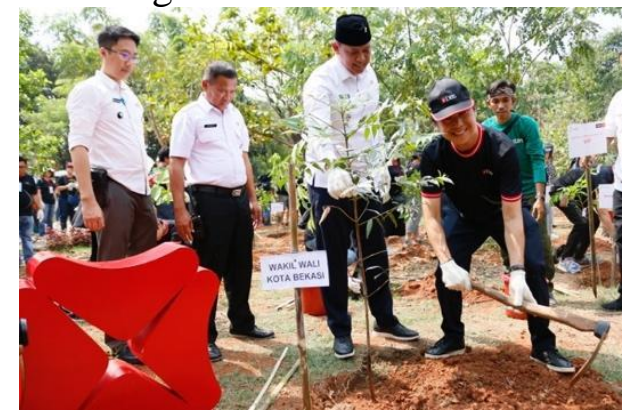

Sumber: Dokumentasi Peneliti (2019)

\section{Kesimpulan}

Berdasarkan hasil penelitian dan pembahasan mengenai strategi media relations yang dilaksanakan Praxis dalam membangun citra Bank DBS Indonesia, dapat ditarik kesimpulan sebagai berikut:

1. Dalam strategi mengelola relasi yang dilakukan Praxis adalah membangun hubungan awal yang baik dengan media. Secara garis besar yang dilakukan praktisi $P R$ Praxis adalah dengan membangun hubungan secara formal dilakukan atas dasar kepentingan pekerjaan dan juga secara informal dilakukan atas dasar membangun hubungan personal yang lebih akrab.

2. Praxis mengembangkan strategi dengan menjalankan prinsip-prinsip umum dalam melaksanakan kegiatan media relations. Hal ini tentunya dilakukan untuk menyampaikan pesan kunci Bank DBS Indonesia, yaitu "Live more, Bank less" pada setiap pemberitaan di media massa.

3. Praxis juga mengembangkan jaringan pekerjaan dengan bidang profesi lainnya, seperti dengan berbagai institusi media, instansi pemerintahan, dan juga dengan komunitas-komunitas lainnya guna menunjang kegiatan atau acara yang diselenggarakan oleh Bank DBS Indonesia.

Beberapa saran Peneliti adalah hendaknya Praxis tetap mempertahankan strategi media relations yang selama ini sudah terlaksana dengan baik, dan juga Praxis dapat lebih memperluas jaringan pekerjaan mereka, terutama pada kalangan milenial. 


\section{Ucapan Terima Kasih}

Puji dan syukur Peneliti panjatkan kepada Tuhan Yang Maha Esa, karena atas berkat dan rahmat-Nya Peneliti dapat menyelesaikan Skripsi ini dengan baik. Dalam penyusunan Skripsi ini Peneliti juga mendapat banyak dukungan dari berbagai pihak lain. Untuk itu sudah sepantasnya Peneliti ucapkan terima kasih juga kepada para narasumber, keluarga, dan sahabat-sahabat Peneliti.

\section{Daftar Pustaka}

Darmastuti, Rini. 2012. Media Relations: Konsep, Strategi \& Aplikasi. Yogyakarta: CV Andi Offset.

Emzir. 2016. Metodologi Penelitian Kualitatif: Analisis Data. Jakarta: Rajagrafindo Persada.

Farleni \& Widayatmoko. 2014. Peran Public Relations Kepolisian Republik Indonesia Melalui Media Relations dalam Membangun Citra yang Lebih Baik. Jurnal Ilmu Komunikasi Vol. 6 No. 1. Oktober 10, 2019. https://journal.untar.ac.id/index.php/komunikasi/article/view/21.

Iriantara, Yosal. 2011. Media Relations: Konsep, Pendekatan, dan Praktik. Bandung: Simbiosa Rekatama Media.

Moleong, Lexy J. 2018. Metodologi Penelitian Kualitatif (Edisi Revisi). Bandung: PT Remaja Rosdakarya.

Ruslan, Rosady. 2016. Manajemen Public Relations dan Media Komunikas: Konsepsi dan Aplikasii. Jakarta: PT Rajagrafindo Persada.

Savitri, Lusia., Setyanto, Yugih., \& Winduwati, Septia. 2016. Strategi Public Relations dalam Membangun Image Eco-Tourism Pulau Lombok. ResearchGate. Oktober 10, 2019. https://www.researchgate.net/publication 1308874935_STRATEGI_PUBLIC_RELATIONS_DALAM_MEMBANGU N_BRAND_IMAGE_ECO-TOURISM_PULAU_LOMBOK

Sudjana, Nana dan Ibrahim. 2009. Penelitian dan Penilaian Pendidikan, Bandung: Sinar Baru Algesindo.

Sugiyono. 2014. Metode Penelitian Kuantitatif, Kualitatif, dan R\&D. Bandung: Alfabeta. 